\title{
Reckoning Health Care and Management Practices Knowledge of Goat Farmers of Punjab
}

\author{
Sukhwinder Singh, Rajesh Kasrija* and Parminder Singh \\ Department of Veterinary and Animal Husbandry Extension Education \\ Guru Angad Dev Veterinary and Animal Sciences University, \\ Ludhiana, India \\ *Corresponding author
}

\section{Keywords}

Goat, Health care,

Knowledge,

Management,

Punjab

Article Info

Accepted:

20 January 2020

Available Online:

10 February 2020

\section{A B S T R A C T}

Present investigation was carried out to estimate health care and management practices knowledge level of goat farmers of Punjab. Information was collected through personal interview schedule from 240 goat farmers ( 40 goat farmers each from all the six agroclimatic zones). Knowledge about vaccination schedule, vaccine, deworming schedule, ectoparasite control, mastitis, cleaning of udder, teat dipping was with $38.33 \%, 26.25 \%$, $51.25 \%, 45.42 \%, 47.50 \%, 48.33 \%$ and $40.00 \%$ goat farmers respectively. $38.75 \%$, $30.00 \%, 44.17 \%, 32.50 \%, 43.75 \%, 44.17 \%, 44.58 \%, 39.58 \%, 45.83 \%$ and $41.67 \%$ goat farmers possessed knowledge about common diseases, zoonotic disease, record keeping, management during adverse climate, method of milking, cleaning of milking utensil, colostrum feeding, weaning of kid, ligation \& disinfection of naval cord and kid deworming respectively. Knowledge about disbudding, castration, tagging, hoof trimming, age estimation by dentition, quarantine and proper disposal of dead goat was with $45.83 \%$, $37.08 \%, 32.50 \%, 34.17 \%, 21.25 \%, 19.58 \%$ and $21.67 \%$ goat farmers respectively. The mean awareness of goat farmers about health and management practices in Punjab was $38.09 \%$ and was in medium category. Also, significant difference $(P<0.01)$ exist between Health \& management knowledge score of different agro-climatic zones of Punjab. It suggest the assessment of knowledge level of goat farmer of a particular area first before organizing any extension activity and the importance of organizing more health and management related extension activities at the doorstep of the farmer.

\section{Introduction}

As per 20th Indian Livestock Census 2019, the goat population in India and in Punjab is 148.88 million and 3.48 lakhs respectively. Goat farming play an important role in the livelihood security of rural resource poor, where the other options for earning livelihood were very limited because of lack of capital, cultivated land and other resources like feed and fodder, and water for irrigation (Kumar et al., 2006). However, poor productivity and lack of scientific knowledge about goat farming proves to be the lacunae behind goat 
production in rural India (Mohan et al., 2009). The goat farming done on scientific guidelines by following latest health care and management practices will result in healthy goat, thereby efficient production from goat farm. In Punjab, a large number of small, marginal and landless farmers are involved in goat farming. Also, now a day, goat farming is practiced on commercial lines. So, a study was planned to estimate health care and management practices knowledge level of goat farmers of Punjab.

\section{Materials and Methods}

On the basis of agro climatic conditions, Punjab state has been divided into six different agro-climatic zones (Mahi and Kingra, 2013), namely Sub mountain undulating zone (Zone I), Undulating plain zone (Zone II), Central plain zone (Zone III), Western plain zone (Zone IV), Western zone (Zone V) and Flood plain zone (Zone VI). Randomly selected 240 goat farmers (40 farmers from each agroclimatic zone) were personally interviewed with the help of pre-structured and pre-tested interview schedule by visiting their farm at field level. 25 questions /items related to health care and management practices knowledge of goat farmers were compiled after scrutinizing relevant literature / research articles, consultation with concerned subject matter specialists, after discussion with field extension personnel and progressive goat farmers. The data was recorded after noting expressed opinion and after observing the things physically at goat farm. Goat farmers possessing knowledge about a particular health care and management practice were assigned one score and those which do not possess knowledge about that particular practice were assigned zero score. Goat farmers were categorized into three categories as low, medium and high knowledge with scores of 0-8, 9-16 and more than 16 respectively. For analysis, simple tabular techniques and appropriate statistical methods were employed by using SPSS version 20.0.

\section{Results and Discussion}

Figure 1 represents awareness percentage of goat farmers about health and management practices in different agro-climatic zones of Punjab. Table 1 indicated that in Punjab, knowledge about vaccination schedule, vaccine, deworming schedule, ectoparasite control, mastitis, cleaning of udder, teat dipping was with $38.33 \%, 26.25 \%, 51.25 \%$, $45.42 \%, 47.50 \%, 48.33 \%$ and $40.00 \%$ goat farmers respectively. Ekambaram et al., (2011) reported that deworming (82.08\%), deticking $(6.67 \%)$ and vaccination $(18.67 \%)$ schedules were followed as preventive health measures in Mahabubnagar goats at Andhra Pradesh. Sabapara et al., (2014) reported that in Navsari district of Gujarat, constraints observed by goat owners regarding health care practices were lack of knowledge about deworming (83.20\%) and high mortality rate in kids (81.20\%). 38.75\%, 30.00\%, 44.17\%, $32.50 \%, 43.75 \%$, $44.17 \%$, $44.58 \%$, 39.58\%, $45.83 \%$ and $41.67 \%$ goat farmers possessed knowledge about common diseases, zoonotic disease, record keeping, management during adverse climate, method of milking, cleaning of milking utensil, colostrum feeding, weaning of kid, ligation \& disinfection of naval cord and kid deworming respectively. Knowledge about disbudding, castration, tagging, hoof trimming, age estimation by dentition, quarantine and proper disposal of dead goat was with $45.83 \%, 37.08 \%, 32.50 \%, 34.17 \%$, $21.25 \%, 19.58 \%$ and $21.67 \%$ goat farmers respectively. The mean awareness of goat farmers about health and management practices in Punjab was $38.09 \%$. Lusweti (2000) reported that in the North west province of South Africa, health care would need to be improved and marketing incentives would need to be introduced. 
Table.1 Awareness percentage of goat farmers about health care and management practices in Punjab

\begin{tabular}{|c|c|c|c|c|c|c|c|}
\hline \multirow[t]{2}{*}{ Awareness about } & \multicolumn{6}{|c|}{ Agro-climatic zone } & \multirow{2}{*}{$\begin{array}{l}\text { Over all } \\
(n=240)\end{array}$} \\
\hline & I $(n=40)$ & II $(n=40)$ & III $(n=40)$ & IV $(n=40)$ & $V(n=40)$ & VI $(n=40)$ & \\
\hline Vaccination schedule & 35.00 & 35.00 & 27.50 & 42.50 & 57.50 & 32.50 & 38.33 \\
\hline Knowledge about vaccine & 25.00 & 35.00 & 15.00 & 35.00 & 17.50 & 30.00 & 26.25 \\
\hline Knowledge about deworming schedule & 35.00 & 40.00 & 65.00 & 47.50 & 70.00 & 50.00 & 51.25 \\
\hline Ecto parasite control & 32.50 & 27.50 & 55.00 & 57.50 & 60.00 & 40.00 & 45.42 \\
\hline Mastitis & 40.00 & 52.50 & 60.00 & 50.00 & 45.00 & 37.50 & 47.50 \\
\hline Cleaning of udder & 35.00 & 35.00 & 55.00 & 65.00 & 55.00 & 45.00 & 48.33 \\
\hline Teat dipping & 32.50 & 35.00 & 52.50 & 55.00 & 37.50 & 27.50 & 40.00 \\
\hline Common diseases & 35.00 & 52.50 & 45.00 & 57.50 & 25.00 & 17.50 & 38.75 \\
\hline Zoonotic disease & 32.50 & 27.50 & 37.50 & 32.50 & 22.50 & 27.50 & 30.00 \\
\hline Record keeping & 42.50 & 30.00 & 37.50 & 60.00 & 65.00 & 30.00 & 44.17 \\
\hline Management during adverse climate & 25.00 & 37.50 & 25.00 & 45.00 & 50.00 & 12.50 & 32.50 \\
\hline Method of milking & 37.50 & 35.00 & 37.50 & 70.00 & 35.00 & 47.50 & 43.75 \\
\hline Cleaning of milking utensil & 37.50 & 40.00 & 45.00 & 37.50 & 55.00 & 50.00 & 44.17 \\
\hline Colostrum feeding & 40.00 & 40.00 & 35.00 & 55.00 & 67.50 & 30.00 & 44.58 \\
\hline Weaning of kid & 27.50 & 22.50 & 47.50 & 55.00 & 70.00 & 15.00 & 39.58 \\
\hline Ligation \& disinfection of naval cord & 45.00 & 32.50 & 47.50 & 52.50 & 70.00 & 28.00 & 45.83 \\
\hline Kid deworming & 27.50 & 27.50 & 60.00 & 27.50 & 70.00 & 37.50 & 41.67 \\
\hline Disbudding & 37.50 & 35.00 & 55.00 & 52.50 & 67.50 & 27.50 & 45.83 \\
\hline Castration & 30.00 & 20.00 & 57.50 & 32.50 & 55.00 & 27.50 & 37.08 \\
\hline Tagging & 37.50 & 20.00 & 45.00 & 30.00 & 47.50 & 15.00 & 32.50 \\
\hline Hoof trimming & 30.00 & 17.50 & 47.50 & 30.00 & 52.50 & 27.50 & 34.17 \\
\hline Age estimation by dentition & 25.00 & 15.00 & 32.50 & 20.00 & 27.50 & 7.50 & 21.25 \\
\hline Quarantine & 15.00 & 12.50 & 40.00 & 12.50 & 25.00 & 12.5 & 19.58 \\
\hline Proper disposal of dead goat & 25.00 & 17.50 & 35.00 & 32.50 & 12.50 & 7.50 & 21.67 \\
\hline Mean percentage & 32.71 & 30.94 & 44.17 & 43.96 & 48.33 & 28.44 & 38.09 \\
\hline
\end{tabular}


Table. 2 Health and management Knowledge score of goat farmers in different agro-climatic zones of Punjab

\begin{tabular}{|l|c|c|}
\hline \multicolumn{1}{|c|}{ Agro-climatic zone } & $\begin{array}{c}\text { Health and management } \\
\text { Knowledge score (Mean } \\
\pm \text { S.E.) }\end{array}$ & $\begin{array}{r}\text { Health and } \\
\text { management } \\
\text { Knowledge level }\end{array}$ \\
\hline Submountain undulating (n=40) & $7.85^{\mathrm{b}} \pm 0.88$ & Low \\
\hline Undulating plain (n=40) & $7.42^{\mathrm{b}} \pm 0.83$ & Low \\
\hline Central plain (n=40) & $10.60^{\mathrm{a}} \pm 0.89$ & Medium \\
\hline Western plain (n=40) & $10.55^{\mathrm{a}} \pm 1.02$ & Medium \\
\hline Western (n=40) & $11.60^{\mathrm{a}} \pm 1.14$ & Medium \\
\hline Flood plain (n=40) & $6.82^{\mathrm{b}} \pm 0.51$ & Low \\
\hline Over all (n=240) & $9.14^{\mathrm{a}} \pm 0.38$ & Medium \\
\hline
\end{tabular}

Figure.1 Awareness percentage of goat farmers about health and management practices in different agro-climatic zones of Punjab

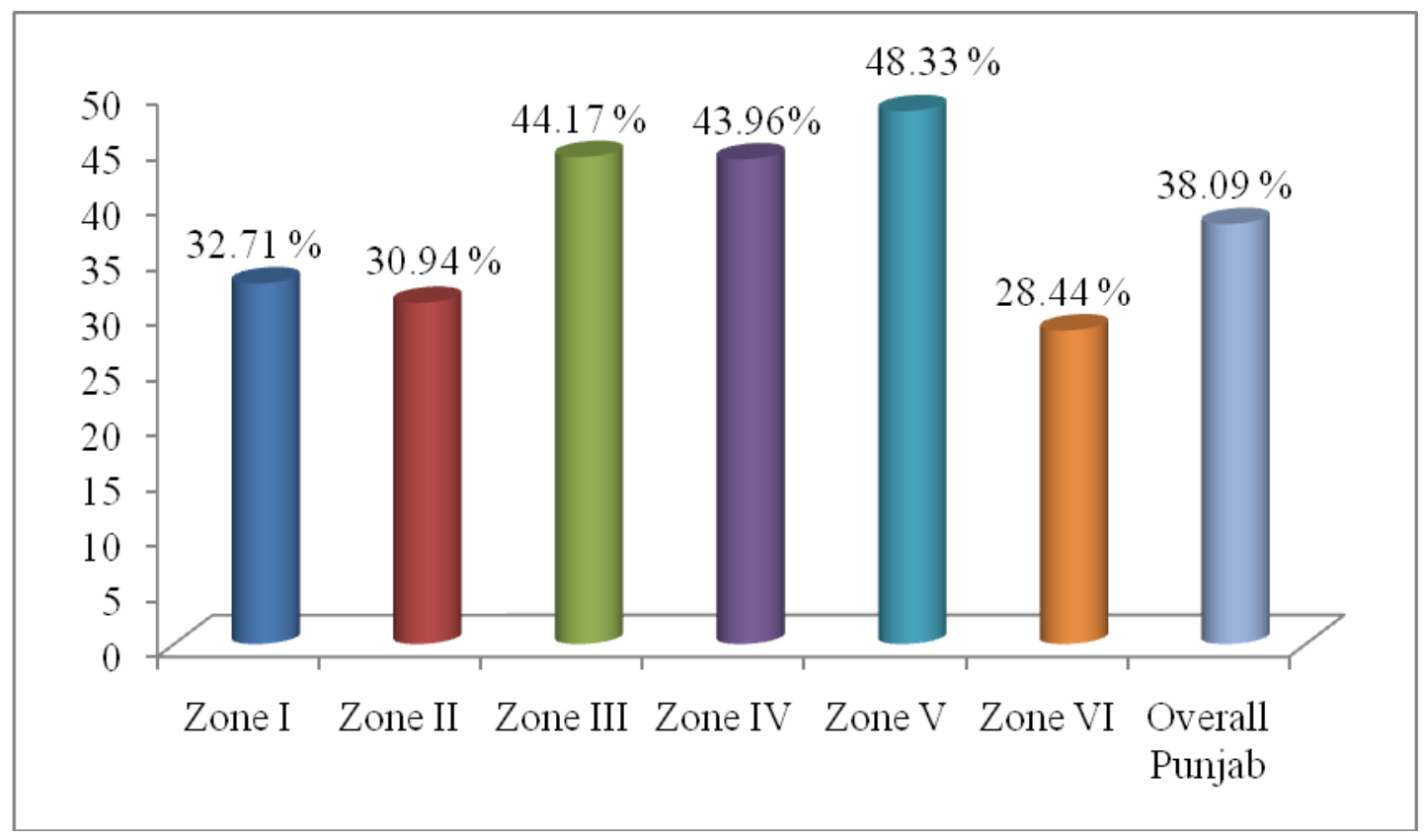


Figure.2 Health \& Management Knowledge score (Mean \pm S.E.) of goat farmers in different agro-climatic zones of Punjab

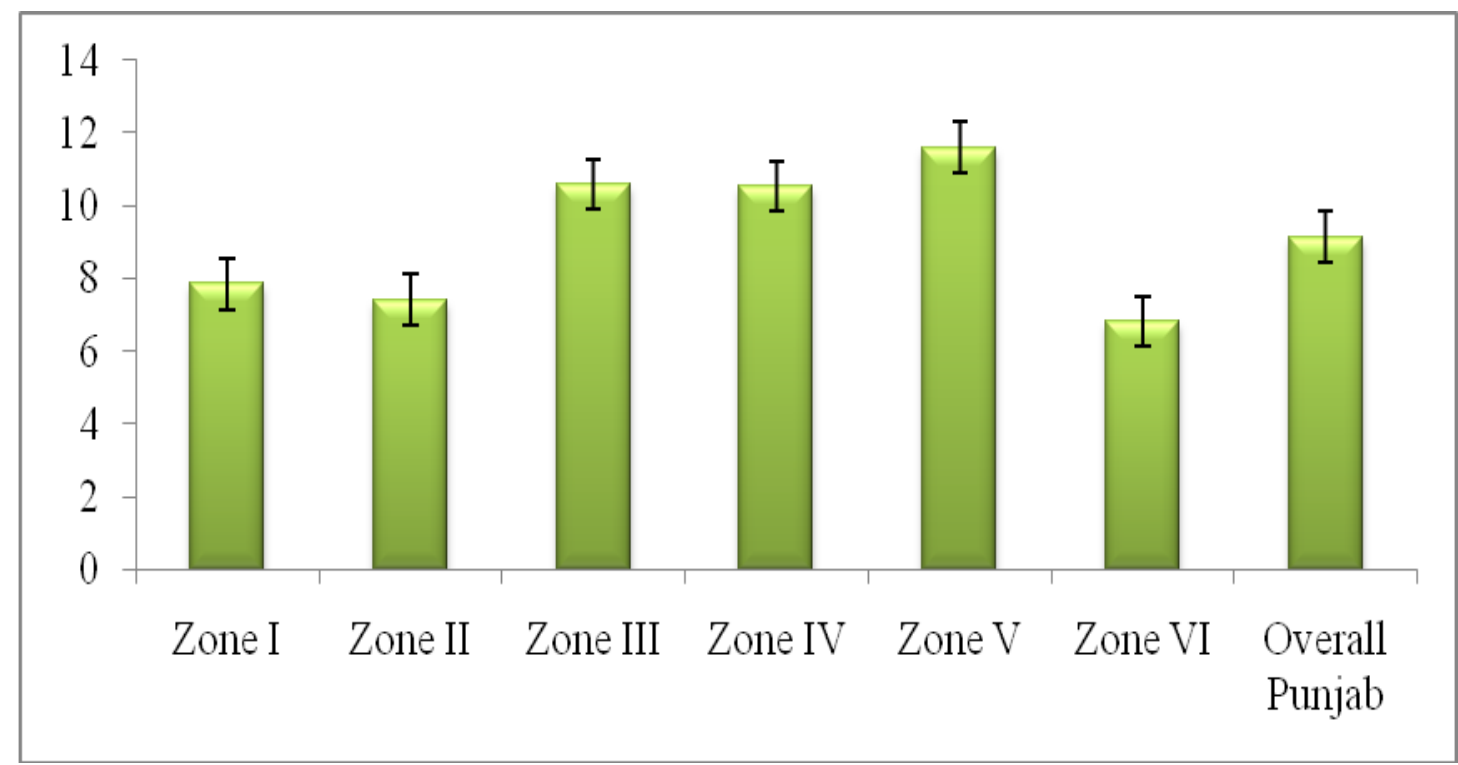

Roy and Tiwari (2017) also reported that in West Bengal and Uttar Pradesh, majority of the goat owners had medium level of knowledge about healthcare management practices.

It is clear from Table 2 and Figure 2 that there was a significant difference $(\mathrm{P}<0.01)$ between Health \& management knowledge score of different agro-climatic zones of Punjab. The health \& management knowledge level of different zones was low to medium. For overall Punjab, the mean Health \& management knowledge level was medium. It suggests that goat farmers of different area had different knowledge. The knowledge about health care and management practices varies from place to place.

\section{References}

Ekambaram B, Gupta B R, Prakash M G, Sudhaker K and Reddy V R. 2011. Housing, breeding and management practices of Mahabubnagar goats. Indian Journal of Animal Sciences 81(8): 875-79.

Kumar S, Vaid R K, and Sagar R L. 2006.
Contribution of goats to livelihood security of small ruminant farmers in semiarid region. Indian Journal of Small Ruminants. 12 (1): 61-66.

Lusweti E C. 2000. A survey of goat production in the developing areas of the North West province of South Africa. Short Communication. South African Journal of Animal Science 30: 34-35.

Mahi and Kingra. 2013. Fundamentals of Agrometerology. Kalyani Publishers, Ludhiana pp 236-40.

Mohan B, Sagar R L and Singh K. 2009. Factors related to promotion of scientific goat farming. Indian Research Journal of Extension Education 9(3): 47-50.

Roy R and Tiwari R 2017. Farmers' knowledge and adoption level on goat healthcare management practices in selected areas of India Bangladesh Journal of Animal Science 46(2): 95-101.

Sabapara G P, Kharadi V B and Sorathiya L M. 2014. Prevalent feeding and breeding management practices of goats in Navsari district - Gujarat. Indo-American Journal of Agriculture and Veterinary Science 2(4) retrieved from http: //www.iajavs.com. 


\section{How to cite this article:}

Sukhwinder Singh, Rajesh Kasrija and Parminder Singh. 2020. Reckoning Health Care and Management Practices Knowledge of Goat Farmers of Punjab. Int.J.Curr.Microbiol.App.Sci. 9(02): 2866-2871. doi: https://doi.org/10.20546/ijcmas.2020.902.326 